\title{
Evaluation of Clinical Team Competence: Case of Saudi Arabia
}

\author{
Dr. Mahaman Moussa ${ }^{1}$, Mr. Hussain Ahmed Sofyani ${ }^{2}$, Mr. Bander Hammad Alblowi ${ }^{3}$, Dr. Fatchima. L. Moussa ${ }^{4}$, \\ Mr. Ahmed albarqi ${ }^{3}$, Mr. Hamad S. ALHarbi ${ }^{5}$, Mr. Yahia Ahmad Oqdi ${ }^{6} \&$ Mr.Saleh Khallaf $^{6}$ \\ ${ }^{1}$ King Saud University, Saudi Arabia \\ ${ }^{2}$ Director of Nursing in ED, RN, BSN, MSN, Nursing Administration \& Education, Ohud General Hospital, \\ Ministry of Health, Saudi Arabia \\ ${ }^{3}$ RN, BSN, MSN, Community nurse, Almeqat General Hospital, Ministry of Health, Saudi Arabia \\ ${ }^{4}$ Assistant Professor, Director of Master in Advanced Nursing Practice, College of Nursing, Medical Surgical \\ Department, Princess Nourah Bint Abdulrahaman University, Riyadh, Kingdom of Saudi Arabia \\ ${ }^{5}$ RN, BSN, MSN, Nursing Education, Hanakyah GeneralHospital, Ministry of Health, Saudi Arabia \\ ${ }^{6}$ RN, BSN, MSN, Nursing Administration, Alansar Hospital, Ministry of Health, Saudi Arabia \\ Correspondence: Dr. Fatchima. L. Moussa RN, BSN, MSN, FNP-BC, DNP, Assistant Professor, Director of \\ Master in Advanced Nursing Practice, College of Nursing, Medical Surgical Department, Princess Nourah Bint \\ Abdulrahaman University, Riyadh, Kingdom of Saudi Arabia. Tel: 96-650-184-4318. E-mail: \\ FLMoussa@pnu.edu.sa
}

Received: December 2, 2019 Accepted: February 5, 2020 Online Published: February 24, 2020

doi:10.5539/gjhs.v12n3p137 URL: https://doi.org/10.5539/gjhs.v12n3p137

\begin{abstract}
Purpose of Review: High-level nurse-doctor collaboration and competence reduce average hospital duration of the patient and mortality rates. Critical care unit plays an integral role as it integrates techniques and principles for ensuring high-quality care in a dynamic work environment. This study determines the status of critical care unit professionals, particularly nurses concerning their teamwork self-assessment. The descriptive correlational study design following a quantitative research design was used. Purposive sampling was employed for selecting 143 critical care unit nurses from Al-Ansar General Hospital, Saudi Arabia. A survey using a teamwork effectiveness self-assessment questionnaire was held for collecting data, which was then statistically analyzed.
\end{abstract}

Recent Findings: Findings showed a significant and positive correlation between nurses' interests and priorities with their job functions and problem-solving abilities. It showed that the manager's support and guidance along with the nurse's participation in decision-making helped the nurses to resolve critical problems and make rapid decisions in critical hours.

Summary: Nurses' conflict management and effective time utilization were significantly and positively correlated. This provided physical and structural opportunities, adequate education and training, and a supportive environment to overcome problems impeding teamwork effectiveness.

Keywords: clinical teams, Critical Care Units, effectiveness, hospital-based interventions, teamwork

\section{Introduction}

An increasing concern is reported among the innovative care models for managing chronic diseases in patients, with a growing need for health care services (Loeb et al., 2018). McNab et al. (2018) write that effective care requires multidisciplinary care, interventional resources, and community-based social networks. Multidisciplinary caregivers in care delivery are one of the essential components of disease management models. Merriel et al. (2016) report that a multidisciplinary team improves patient satisfaction, care integration, administrative procedures, and patients' care outcomes. It is the reason that promoting a multidisciplinary team approach is viewed as a means for providing efficient and effective care integrating different abilities of health care professionals.

These health care professionals determine high-risk groups for the care delivery and emphasize on lowering these stressors with interventions delivered throughout the ICU (Vijayaraghavan, Willaert, \& Cuthbertson, 2018). The consequences of failed integration of clinical teams' efforts can be far-reaching and severe, which substantially increases their work burden. If interventions disrupt workflow, the quality of patient care and the impact of 
treatment efficacy is adversely affected (Omura, Maguire, Levett-Jones, \& Stone, 2017). The difficulty to implement care models substantially affects the teamwork capacity, which stresses them to implement new alternative interventions. Increasing the potential of a smooth, sustainable, and cost-effective process of change allow understanding the barriers and facilitators to successfully deliver effective care (Branowicki et al., 2017).

Healthcare organizations experience challenges in delivering effective complex interventions (Shah, Forsythe, \& Murray, 2018). Thus, the integration of new interventions in both organizational and health ramifications has become necessary (Wells et al., 2018). Professional behaviors are easily targeted in these interventions, but most of them are not directed. However, the rationale behind their efforts and integration is usually reactive for remedial action and systemic weaknesses (Killaspy et al., 2015). For instance, the development of ward-based improvement interventions was one of the models to follow a series of high-profile public queries into the quality of United Kingdom (UK) healthcare systems (McKee, Codd, Dempsey, Gallagher, \& Comiskey, 2017). Instead, the integration of such interventions is usually not managed. For instance, Geerligs, Rankin, Shepherd, and Butow (2018) highlight that about $60 \%$ of all newly implemented interventions fail due to funding restrictions.

Despite the challenges, team members also experience several perceived benefits such as a sense of being valued, respected and trusted, help in workload sharing, improved sense of well-being, and learning from others' expertise (Gogovor, Burnand, Ahmed, Montague, \& Peytremann-Bridevaux, 2012). The "romance of teams" phenomenon refers to the common assumption that teams are a very effective and follow an integrated healthcare work structure (Linden \& Butterworth, 2014). Studies note that effective teamwork is important for assuring better patient care in the critical care unit (CCU) (Cowie, Campbell, Dimova, Nicoll, \& Duncan, 2018; Killaspy et al., 2015; Wells et al., 2018). Studies indicate that most of the medical errors are due to poor communication among team members during in-patient rounds (D'Angelo, Cervero, Durning, \& Varpio, 2019; Rosen et al., 2018). Rosen et al. (2018) report that ineffective communication leads to the occurrence of approximately $28 \%$ of adverse surgical cases. Although, various researches have been conducted on the healthcare nurses in Saudi Arabia (Alharbi, Jackson, \& Usher, 2019; Alharbi, Wilson, Woods, \& Usher, 2016; Awajeh, Issa, Rasheed, \& Amirah, 2018), the self-assessment of the CCU nurses has remained an unexplored research area. Thereby, to bridge this gap, this study aims to determine the status of CCU professionals, particularly nurses concerning their self-assessment of teamwork. The study is motivated that teamwork competence and effectiveness have interrelatedness based on the responses of CCU nurses. Furthermore, this study determines the impact of the competence and effectiveness of nurses in the health care services' delivery such as patients' safety and quality services in CCU approach and managing situations with their workmates, environment, and patients. This research is of substantial relevance to the emerging self-assessed competence aspect. It helps the modern and well-resource hospitals that offer in-service programs to nurses across different clinical units, particularly in CCU.

\subsection{Literature Review}

Team members are socially competent and prefer to share information, solve issues, and negotiate decisions. Clinical teams require a specific level of confidence and self-knowledge in their professional skills and role for communicating well and developing a sense of commitment (Ervin, Kahn, Cohen, \& Weingart, 2018). However, they also need adequate levels of recognition, encouragement, and respect when working in teams. Indeed, there are inevitable conflicts between the organization, individuals, and other team members. Respectful, responsive, and flexible workforce development opportunities are essential in maintaining team effectiveness (Moore, Everly, \& Bauer, 2016). Distributive activity among team members and encouraging individual performance improves team efficiency (McCulloch et al., 2017).

Patients, stakeholders, and team members usually evaluate and prefer team consequences differently because effectiveness is both a political and empirical concept. Determinants of team effectiveness are usually presented in the form of the individual, team, and organizational benefits (Kim, Song, Lindquist, \& Kang, 2016). Organizational benefits of teamwork have been explained as decreased hospitalization time and costs, better patient accessibility, enhanced care coordination, and fewer unanticipated admissions. The efficient use of services, maximal diversity of professional expertise, and improved communication are included in team-level benefits (Gluyas, 2015).

Measuring the effectiveness of teams is essential, for organizations focused on team performance. One important reason is that the effectiveness of a team can produce more benefits such as productivity, employee attitudes, quality, and workplace efficiency (McEwan, Ruissen, Eys, Zumbo, \& Beauchamp, 2017). Secondly, stakeholders are looking for a return on investment for the costs related to supporting the work team structure in an organization. Effective problem-solving is important for individual contributors and work teams (O'Malley, Gourevitch, Draper, Bond, \& Tirodkar, 2015). For instance, a collaborative problem-solving dimension helps in identifying situations 
where group members work together to solve problems (Currey, Eustace, Oldland, Glanville, \& Story, 2015).

Team commitment is represented in the form of willingness, turnover, and productivity of employees that help boost team performance (Galletta, Portoghese, Carta, D'Aloja, \& Campagna, 2016). Absenteeism, intention to quit and turnover are associated with low commitment levels to both the team and the organization (Galletta, Portoghese, Coppola, Finco, \& Campagna, 2016). Commitment is thus explained as the state of being intellectually or emotionally bonded to the objective and team members. Communication emphasizes on teamwork process and; therefore, differentiates between ineffective and effective teams (Gluyas, 2015). A team is only as good as the ability of each member to communicate effectively, which includes adequate information sharing, appropriate perception, and interpretation, effective listening skills, and appropriately attending the non-verbal cues (Thomson, Outram, Gilligan, \& Levett-Jones, 2015).

Grubaugh and Flynn (2018) indicates that conflict relies on how the team members control, resolve and manage the problem. Teams need to support and reflect on the occurred conflict over significant issues that require time to consider the causes of the conflict and ways to overcome it (Grubaugh \& Flynn, 2018). Although, at times, an issue may not be completely overcome, however, they should be minimized. This issue is frequently experienced among teams working in a large organization, even after repeated training sessions (Eichbaum, 2018).

The importance of continuous improvement involves producing a constant stream of improvements for customer value creation including timely delivery, quality, and design (McNab et al., 2018). The only evaluation that measured continuous improvement is team effectiveness even though its concepts were covered in some of the individual items of team evaluations. The implementation of different concepts and items promotes continuous improvements and leads to reduced response time, improved quality and customer service, simplified design of both procedures and products, and eliminated waste (Killaspy et al., 2015).

\section{Material and Methods}

\subsection{Study Design}

Descriptive correlational study design was used to determine the role of CCU nurses' competence in performing hospital-based interventions. The study used a quantitative approach for examining the research findings and numerically presenting it.

\subsection{Study Sample and Population}

Nurses in the critical care unit served as the research population, who were then recruited using a purposive sampling technique. The participants were selected based on the inclusion or eligibility criteria developed for answering the study objective. The inclusion criteria include (1) nurses who have been working and assigned particularly in CCU, and (2) nurses working in Al-Ansar General Hospital (AGH), Al-Madinah, Saudi Arabia. G-power analysis was used to determine the sample size which represents the CCU nurses in this specific region in AGH.

\subsection{Data Collection}

A structured questionnaire was used as a study instrument for collecting the data from the potential participants. Cronbach's alpha was used to test the reliability of the instrument using a pilot study with 10 participants. These participants were excluded from the sample list in the final survey. The questionnaire was self-developed, which was originally proposed by Sterling and Selesnick (1988). A 5-point Likert scale measuring tool was used to measure the items $(\mathrm{n}=11)$ from 1 to 5 (strongly agree to strongly disagree). A total score of less than 40 indicates teamwork effectiveness issues.

\subsection{Data Collection Procedure}

Initially, researcher sent an email to the Nurse Directorate at the hospital which contained a complete explanation of the study, its research objective, scope, and contribution. After attaining an approval, the email was forwarded to the critical care nurses at the hospital, inviting them for survey participation. The developed questionnaire was then formulated on Google Form and was made available online for the nurses. The link of the questionnaire was forwarded to the nurses, along with the completion duration of four weeks. The researcher also sent two reminders to the nurses for the timely completion of the questionnaire.

\subsection{Ethical Consideration}

The Institutional Review Board (IRB) of King Saud University-College of Medicine (KSU-COM) provided approval along with the ethical clearance. AGH is considered as the research setting for data collection. The research instrument was distributed to the participants after their eligibility based on the inclusion criteria and 
informed consent. The structured questionnaire was distributed to the participants and collected using an envelope for preserving anonymity and confidentiality. The researchers might assist the clinic or areas and the staff in the hospital.

\section{Data Analysis}

Data were analyzed using IBM SPSS (Statistical Package for Social Sciences) version 21.0. The categorical study variables and other quantitative variables were presented using descriptive statistics such as frequency, average weighted mean, and percentage. The relationship between teamwork effectiveness factors was determined through the Spearman rank correlation. The statistical significance was determined through a p-value of $<0.05$ and $95 \%$ confidence intervals for the difference of mean to derive inferences.

\section{Results}

Table 1 presents the demographic characteristics of 143 nurses working in Al-Nasar General Hospital. Most of the nurses were $26-41$ years old (26.57\%), followed by $42-60$ years old $(26.57 \%$ ), and $20-25$ years old $(22.3 \%) .47 .55 \%$ of nurses hold a Bachelor's degree while $25.87 \%$ of nurses hold associate degrees. $34.2 \%$ of nurses had work experience of 3-5 years in Al-Nasar General Hospital, while only $12.5 \%$ of nurses were having more than 10 years of experience.

Table 1. Demographic Characteristics

\begin{tabular}{|c|c|c|c|}
\hline Variables & & Frequency & Percentage \\
\hline \multicolumn{4}{|l|}{ Age } \\
\hline & $20-25$ years & 32 & $22.3 \%$ \\
\hline & $26-41$ years & 73 & $51 \%$ \\
\hline & $42-60$ years & 38 & $26.57 \%$ \\
\hline \multicolumn{4}{|c|}{ Education Level } \\
\hline & Associate Degree & 37 & $25.87 \%$ \\
\hline & Diploma & 14 & $9.7 \%$ \\
\hline & Bachelor & 68 & $47.55 \%$ \\
\hline & Master & 24 & $16.7 \%$ \\
\hline \multicolumn{4}{|c|}{ Years of Experience } \\
\hline & $<1$ Year & 15 & $10.4 \%$ \\
\hline & 1-3 Years & 35 & $24.4 \%$ \\
\hline & 3-5 Years & 49 & $34.2 \%$ \\
\hline & 5-10 Years & 26 & $18.18 \%$ \\
\hline & $>10$ Years & 18 & $12.5 \%$ \\
\hline
\end{tabular}

Spearman rank correlation has been applied to determine the effectiveness of Saudi nurses in terms of different teamwork effectiveness problems. Table 2 provides a correlation between interests and priorities, problem-solving abilities, and organization of team structure. The findings have shown a significant and positive correlation between interests and priorities set by nurses linked with the priorities of their job functions with problem-solving abilities $(\mathrm{r}=0.169, \mathrm{p}=0.009)$ and able to perform the tasks appropriately under the organized team structure $(\mathrm{r}=$ $0.77, \mathrm{p}=0.033)$. 
Table 2. Spearman Correlation between Interests and Priorities, Solving Problem Abilities, and Organized Team Structure

\begin{tabular}{|c|c|c|c|c|c|}
\hline \multicolumn{6}{|l|}{ Correlations } \\
\hline & & & $\begin{array}{l}\text { Interests } \\
\text { Priorities }\end{array}$ & $\begin{array}{l}\text { Solving } \\
\text { Problems }\end{array}$ & $\begin{array}{l}\text { Organized } \\
\text { Structured }\end{array}$ \\
\hline \multirow[t]{9}{*}{ Spearman's rho } & Interests Priorities & Correlation Coefficient & 1.000 & .169 & .077 \\
\hline & & Sig. (2-tailed) & . & .009 & .033 \\
\hline & & $\mathrm{N}$ & 143 & 143 & 143 \\
\hline & Solving Problems & Correlation Coefficient & .169 & 1.000 & $-.188^{*}$ \\
\hline & & Sig. (2-tailed) & .009 & . & .024 \\
\hline & & $\mathrm{N}$ & 143 & 143 & 143 \\
\hline & Organized Structured & Correlation Coefficient & .077 & $-.188^{*}$ & 1.000 \\
\hline & & Sig. (2-tailed) & .033 & .024 & . \\
\hline & & $\mathrm{N}$ & 143 & 143 & 143 \\
\hline
\end{tabular}

*. Correlation is significant at the 0.05 level (2-tailed).

Tables 3 and 4 presents a correlation between effective problem-solving and decision-making methods, and high-level decision-making participation and guidance utilized to determine nurse's effectiveness in CCU. The findings show that nurses lack in making effective decisions based on their problem-solving methods $(r=-.120, p$ $=.152$ ). However, high-level decision-making participation and guidance provided by managers were important factors, which help them in solving critical problems and making decisions in critical hours $(\mathrm{r}=.553, \mathrm{p}=.032)$ (Table 4).

Table 3. Spearman Correlation between Effective Problem-Solving and Decision-Making Methods

\begin{tabular}{lllll}
\hline Correlations & & & & \\
\hline & & & $\begin{array}{l}\text { Problem } \\
\text { Procedures Methods }\end{array}$ & $\begin{array}{l}\text { Solving } \\
\text { Decision-making } \\
\text { methods }\end{array}$ \\
\hline $\begin{array}{l}\text { Spearman's } \\
\text { rho }\end{array}$ & $\begin{array}{l}\text { Problem Solving Procedures } \\
\text { Methods }\end{array}$ & $\begin{array}{l}\text { Correlation } \\
\text { Coefficient }\end{array}$ & 1.000 & -.120 \\
& & Sig. (2-tailed) &. & .152 \\
& $\mathrm{~N}$ & 143 & 143 \\
& Decision-making methods & Correlation & -.120 & 1.000 \\
& Coefficient & &. \\
& Sig. (2-tailed) & .152 & 143 \\
\hline
\end{tabular}


Table 4. Spearman Correlation between High-Level Decision-Making Participation and Guidance Utilized

\begin{tabular}{lllll}
\hline Correlations & & & \\
\hline & & & Participation & Guidance \\
\hline & \multirow{2}{*}{ Participation } & Correlation Coefficient & 1.000 & .553 \\
& & Sig. (2-tailed) &. & .032 \\
\cline { 2 - 5 } Spearman's rho & $\mathrm{N}$ & 143 & 143 \\
& \multirow{3}{*}{ Guidance } & Correlation Coefficient & .553 & 1.000 \\
& & Sig. (2-tailed) & .032 & 143 \\
\hline
\end{tabular}

Honest team members' expressions and expectations are usually considered as important factors when determining the effectiveness of team members specifically nurses in CCU. The results show that significant and positive correlation is found between honest expressions and expectations of team members when working in $\mathrm{CCU}$ at Al-Nasar General Hospital $(\mathrm{r}=.465, \mathrm{p}=.043)$ (Table 5). Similarly, nurses' conflict management and effective time utilization were significantly and positively correlated $(\mathrm{r}=.879, \mathrm{p}=.013)$ (Table 6).

Table 5. Spearman Correlation between Honest Expressions and Team Members Expectations

\begin{tabular}{lllll}
\hline Correlations & & & & \\
\hline & & & Expression & Expectation \\
\hline & \multirow{2}{*}{ Expression } & Correlation Coefficient & 1.000 & .465 \\
& & Sig. (2-tailed) &. & .043 \\
\cline { 2 - 5 } Spearman's rho & $\mathrm{N}$ & Correlation Coefficient & .465 & 143 \\
& \multirow{3}{*}{ Expectation } & Sig. (2-tailed) & .043 & 1.000 \\
& & $\mathrm{~N}$ & 143 & 143 \\
\hline
\end{tabular}

Table 6. Spearman Correlation between Effective Time Utilization and Handling Conflicts

\begin{tabular}{lllll}
\hline Correlations & & & Time spending & Conflict \\
\hline \multirow{3}{*}{ Spearman's rho } & \multirow{3}{*}{ time spending } & Correlation Coefficient & 1.000 & .879 \\
& & Sig. (2-tailed) &. & .013 \\
& & $\mathrm{~N}$ & 143 & 143 \\
\cline { 2 - 5 } & \multirow{3}{*}{ conflict } & Correlation Coefficient & .879 & 1.000 \\
& & Sig. (2-tailed) & .013 &. \\
& & $\mathrm{~N}$ & 143 & 143 \\
\hline
\end{tabular}

Table 7 presents the ranking for teamwork effectiveness problems experienced by nurses in CCU. Based on the responses of nurses, there were 4 problems experienced by nurses in $\mathrm{CCU}$, including problem-solving methods, organized team structuring, decision-making methods, and honest team members' expression. Patients have rated conflict management to be the most effective aspect of their teamwork effectiveness, followed by the guidance provided by managers, and team members' expectations. 
Table 7. Spearman Ranking for Teamwork Effectiveness Problems

\begin{tabular}{lll}
\hline Variables & Scoring* & Ranking \\
\hline Interests and Priorities & 40 & 7 \\
Problem Solving Abilities & 46 & 4 \\
Organized Team Structuring & 35 & 9 \\
Problem-Solving Methods & 30 & 11 \\
Decision-Making Methods & 39 & 8 \\
High-Level Decision-Making Participation & 45 & 5 \\
Guidance Utilization & 53 & 2 \\
Honest Team Members Expression & 32 & 10 \\
Effective Time Utilization & 41 & 6 \\
Team Members Expectations & 52 & 3 \\
Conflict Management & 55 & 1 \\
\hline
\end{tabular}

*Scoring less than 40 indicates teamwork effectiveness problem.

\section{Discussion}

The study has determined the status of CCU professionals, specifically among nurses in terms of teamwork effectiveness. Using a descriptive correlational design, it showed that there is a significant and positive correlation between nurses' interests and priorities associated with their job functions and problem-solving abilities. High-level decision-making participation and guidance provided by managers were important in solving critical problems and making decisions in critical hours. Nurses' conflict management and effective time utilization were significantly and positively interrelated. Patients have rated conflict management as the most effective aspect of their teamwork effectiveness, followed by the guidance provided by managers, and team members' expectations.

Previous studies have reported that encouraging competitive teams can benefit staff and the organizations assisting in forming collaborative quality culture and safety (Drayton-Brooks, Gray, Turner, \& Newland, 2017; Etherington, Wu, Cheng-Boivin, Larrigan, \& Boet, 2019; Sinha, 2017). Greater perceptions of empowerment and identification are also included in other benefits to the team. This might be due to a more horizontal power structure, greater levels of role understanding, and more open and inclusive communication as compared to hierarchical structures among competent teams (Foronda, MacWilliams, \& McArthur, 2016). The drivers or determinants of competent practice involve the procedures, behaviors, and content of the team.

The findings show that managers assist the nurses in effective decision making. This might be due to their practicing strategies. The strategic content used by managers includes team strategies and vision that assist the team to clarify and direct as a cohesive group that values the diversity among its members. Procedures are the organizational structures in which the team operates such as procedures, management effects, and policies (Sims, Hewitt, \& Harris, 2015). These procedures can make team collaborations more objective, inclusive, transparent, and less emotional and personal. The behaviors are the internally driven interactions and actions of the team members. A successful and motivated team will have members that are trustworthy and accountable to one another, feel protected to behave in transparent and open ways, and accept their differences and interdependency (Sangaleti, Schveitzer, Peduzzi, Zoboli, \& Soares, 2017).

Members have different interests, goals, experiences, styles, and expectations that create difficulty in the communication process and generate conflict throughout the team. Therefore, team leaders manage these unique interests and maximize the strengths of the team structuring (Rosen et al., 2018). Interprofessional teams may include members with different levels of prestige, salary, and authority that create a challenge to manage and negotiate power arrangements. A team leader might be competent for facilitating the authority and responsibility negotiation issues, which are subjected to the complicated associations of a team.

In the healthcare setting, all these challenges apply where the professional disciplines are involved in having different roles, prestige, pay, supporting organizational structures, education, and responsibilities. Previous studies have indicated that a professional with greater experience and skills, higher levels of psychological safety, and greater understanding and alignment with team goals might be more appropriate for involving incompetent 
practices (Ambrose-Miller \& Ashcroft, 2016; Körner et al., 2016). However, lack of trust and poor communication can create challenges in team effectiveness in which conflict and psychological safety may be affected.

\subsection{Recommendation}

This research serves as a preliminary benchmarking material for effective nurse management in Saudi hospitals. Based on the findings, it is recommended that different training and competence screening programs and policies should be introduced for ensuring the presence of relevant skills and capabilities. This self-assessment competence can be used in educational nursing planning and made part of the nursing curricula for ensuring the delivery of quality care. Also, for integrating trust among the team members, different collaborative programs and interventions should be introduced where discussions must be promoted. These discussions must be central to the issues experienced during care delivery, where team members must be asked to rethink the situation and the practices that could help overcome such problems. This also helps devise strategies to resolve any potential problems and setbacks.

Different workshops should also be held for integrating coordination in the team which helps make the work environment more integrating, less excruciating as well as positive. The health management system should also be encouraged for nurse competence screening, which includes nurse prescreening, knowledge assessment as well as a reassessment for addressing the challenges as a team member. This assessment would also assist in improving nurse self-esteem as a professional promoting him/her to deliver qualified and quality care.

\section{Conclusion}

The findings conclude that an interprofessional and competent team encourages safe and high-quality care, organizational efficiency and innovation, patient and staff engagement and satisfaction. It shows that providing physical and structural opportunities, adequate education and training, and a supportive environment are all important for overcoming teamwork effectiveness problems. The teamwork can bring quality in the services for the patients to provide services effectively and efficiently to develop their capacities and managing conflicts.

Team members, specifically those in leadership positions or with higher status, should actively make efforts for promoting team members to voice all of their information. They should also serve as role models to express appreciation for diverse knowledge from all sources and assure that input from all team members is considered and used in building team activities work. This practice helps the team to capitalize on their expertise, provide effective patient care, and avoid errors.

\section{Key Points}

- High-level decision-making participation and guidance solve critical problems.

- Interests and priorities set by nurses are associated with their job functions.

- Conflict management is an important aspect of teamwork effectiveness.

\section{Acknowledgments}

The author is very thankful to all the associated personnel in any reference that contributed to/for this research. Further, this research holds no conflict of interest and is not funded through any source.

\section{Competing Interests Statement}

The authors declare that there are no competing or potential conflicts of interest.

\section{References}

Alharbi, J., Jackson, D., \& Usher, K. (2019). Personal characteristics, coping strategies, and resilience impact on compassion fatigue in critical care nurses: A cross-sectional study. Nursing \& health sciences. https://doi.org/10.1111/nhs.12650

Alharbi, J., Wilson, R., Woods, C., \& Usher, K. (2016). The factors influencing burnout and job satisfaction among critical care nurses: a study of Saudi critical care nurses. Journal of nursing management, 24(6), 708-717. https://doi.org/10.1111/jonm.12386

Ambrose-Miller, W., \& Ashcroft, R. (2016). Challenges faced by social workers as members of interprofessional collaborative health care teams. Health \& social work, 41(2), 101-109. https://doi.org/10.1093/hsw/hlw006

Awajeh, A., Issa, M., Rasheed, A., \& Amirah, M. (2018). Burnout among Critical Care Nurses in King Saud Medical City (KSMC). J Nurs Care, 7(450), 2167-1168.1000450. https://doi.org/0.4172/2167-1168.1000450

Branowicki, P. M., Vessey, J. A., Graham, D. A., McCabe, M. A., Clapp, A. L., Blaine, K., . . Kline, N. E. (2017). 
Meta-analysis of clinical trials that evaluate the effectiveness of hospital-initiated postdischarge interventions on hospital readmission. The Journal for Healthcare Quality (JHQ), 39(6), 354-366. https://doi.org/10.1097/jhq.0000000000000057

Cowie, J., Campbell, P., Dimova, E., Nicoll, A., \& Duncan, E. A. (2018). Improving the sustainability of hospital-based interventions: a study protocol for a systematic review. BMJ open, 8(9), e025069. https://doi.org/10.1136/bmjopen-2018-025069

Currey, J., Eustace, P., Oldland, E., Glanville, D., \& Story, I. (2015). Developing professional attributes in critical care nurses using Team-Based Learning. Nurse education in practice, 15(3), 232-238. https://doi.org/10.1016/j.nepr.2015.01.011

D'Angelo, M., Cervero, R., Durning, S., \& Varpio, L. (2019). The Teamwork Model: Proposing a Model for Studying Interprofessional Healthcare Teams. https://doi.org/10.15694/mep.2019.000081.1

Drayton-Brooks, S. M., Gray, P. A., Turner, N. P., \& Newland, J. A. (2017). Building clinical education training capacity in nurse practitioner programs. Journal of Professional Nursing, 33(6), 422-428. https://doi.org/10.1016/j.profnurs.2017.02.002

Eichbaum, Q. (2018). Collaboration and teamwork in the health professions: rethinking the role of conflict. Academic Medicine, 93(4), 574-580. https://doi.org/10.1097/acm.0000000000002015

Ervin, J. N., Kahn, J. M., Cohen, T. R., \& Weingart, L. R. (2018). Teamwork in the intensive care unit. American Psychologist, 73(4), 468. https://doi.org/10.1037/amp0000247

Etherington, N., Wu, M., Cheng-Boivin, O., Larrigan, S., \& Boet, S. (2019). Interprofessional communication in the operating room: a narrative review to advance research and practice. Canadian Journal of Anesthesia/Journal canadien d'anesthésie, 66(10), 1251-1260. https://doi.org/10.1007/s12630-019-01413-9

Foronda, C., MacWilliams, B., \& McArthur, E. (2016). Interprofessional communication in healthcare: An integrative review. Nurse education in practice, 19, 36-40. https://doi.org/10.1016/j.nepr.2016.04.005

Galletta, M., Portoghese, I., Carta, M. G., D'Aloja, E., \& Campagna, M. (2016). The effect of nurse-physician collaboration on job satisfaction, team commitment, and turnover intention in nurses. Research in Nursing \& Health, 39(5), 375-385. https://doi.org/10.1002/nur.21733

Galletta, M., Portoghese, I., Coppola, R. C., Finco, G., \& Campagna, M. (2016). Nurses well-being in intensive care units: study of factors promoting team commitment. Nursing in critical care, 21(3), 146-156. https://doi.org/10.1111/nicc.12083

Geerligs, L., Rankin, N. M., Shepherd, H. L., \& Butow, P. (2018). Hospital-based interventions: a systematic review of staff-reported barriers and facilitators to implementation processes. Implementation Science, 13(1), 36. https://doi.org/10.1186/s13012-018-0726-9

Gluyas, H. (2015). Effective communication and teamwork promotes patient safety. Nursing Standard (2014+), 29(49), 50. https://doi.org/10.7748/ns.29.49.50.e10042

Gogovor, A., Burnand, B., Ahmed, S., Montague, T., \& Peytremann-Bridevaux, I. (2012). Team effectiveness in patient health management: an overview of reviews. International Journal of Clinical Medicine, 3(07), 614-627. https://doi.org/10.4236/ijcm.2012.37111

Grubaugh, M. L., \& Flynn, L. (2018). Relationships among nurse manager leadership skills, conflict management, and unit teamwork. JONA: The Journal of Nursing Administration, 48(7/8), 383-388. https://doi.org/10.1097/nna.0000000000000633

Killaspy, H., Marston, L., Green, N., Harrison, I., Lean, M., Cook, S., . . Leavey, G. (2015). Clinical effectiveness of a staff training intervention in mental health inpatient rehabilitation units designed to increase patients' engagement in activities (the Rehabilitation Effectiveness for Activities for Life [REAL] study): single-blind, cluster-randomised controlled trial. The Lancet Psychiatry, 2(1), 38-48. https://doi.org/10.1016/s2215-0366(14)00050-9

Kim, H.-R., Song, Y., Lindquist, R., \& Kang, H.-Y. (2016). Effects of team-based learning on problem-solving, knowledge and clinical performance of Korean nursing students. Nurse education today, 38, 115-118. https://doi.org/10.1016/j.nedt.2015.12.003

Körner, M., Bütof, S., Müller, C., Zimmermann, L., Becker, S., \& Bengel, J. (2016). Interprofessional teamwork 
and team interventions in chronic care: A systematic review. Journal of interprofessional care, 30(1), 15-28. https://doi.org/10.3109/13561820.2015.1051616

Linden, A., \& Butterworth, S. W. (2014). A comprehensive hospital-based intervention to reduce readmissions for chronically ill patients: a randomized controlled trial. Am J Manag Care, 20(10), 783-792.

Loeb, D. F., Leister, E., Ludman, E., Binswanger, I. A., Crane, L., Dickinson, M., . . Bayliss, E. A. (2018). Factors associated with physician self-efficacy in mental illness management and team-based care. General hospital psychiatry, 50, 111. https://doi.org/10.1016/j.genhosppsych.2017.11.003

McCulloch, P., Morgan, L., New, S., Catchpole, K., Roberston, E., Hadi, M., . . Griffin, D. (2017). Combining systems and teamwork approaches to enhance the effectiveness of safety improvement interventions in surgery. Annals of surgery, 265(1), 90-96. https://doi.org/10.1097/sla.0000000000001589

McEwan, D., Ruissen, G. R., Eys, M. A., Zumbo, B. D., \& Beauchamp, M. R. (2017). The effectiveness of teamwork training on teamwork behaviors and team performance: a systematic review and meta-analysis of controlled interventions. PloS one, 12(1). https://doi.org/10.1371/journal.pone.0169604

McKee, G., Codd, M., Dempsey, O., Gallagher, P., \& Comiskey, C. (2017). Describing the implementation of an innovative intervention and evaluating its effectiveness in increasing research capacity of advanced clinical nurses: using the consolidated framework for implementation research. BMC nursing, 16(1), 21. https://doi.org/10.1186/s12912-017-0214-6

McNab, D., Bowie, P., Ross, A., MacWalter, G., Ryan, M., \& Morrison, J. (2018). Systematic review and meta-analysis of the effectiveness of pharmacist-led medication reconciliation in the community after hospital discharge. BMJ Qual Saf, 27(4), 308-320. https://doi.org/10.1136/bmjqs-2017-007087

Merriel, A., van der Nelson, H. A., Lenguerrand, E., Chung, Y., Soar, J., Ficquet, J., . . Siassakos, D. (2016). Emergency training for in-hospital-based healthcare providers: effects on clinical practice and patient outcomes. Cochrane Database of Systematic Reviews, 2016(5). https://doi.org/10.1002/14651858.cd012177

Moore, J. M., Everly, M., \& Bauer, R. (2016). Multigenerational challenges: Team-building for positive clinical workforce outcomes. Online journal of issues in nursing, 21(2).

O’Malley, A. S., Gourevitch, R., Draper, K., Bond, A., \& Tirodkar, M. A. (2015). Overcoming challenges to teamwork in patient-centered medical homes: a qualitative study. Journal of general internal medicine, 30(2), 183-192. https://doi.org/10.1007/s11606-014-3065-9

Omura, M., Maguire, J., Levett-Jones, T., \& Stone, T. E. (2017). The effectiveness of assertiveness communication training programs for healthcare professionals and students: A systematic review. International journal of nursing studies, 76, 120-128. https://doi.org/10.1016/j.ijnurstu.2017.09.001

Rosen, M. A., DiazGranados, D., Dietz, A. S., Benishek, L. E., Thompson, D., Pronovost, P. J., \& Weaver, S. J. (2018). Teamwork in healthcare: Key discoveries enabling safer, high-quality care. American Psychologist, 73(4), 433. https://doi.org/10.1037/amp0000298

Sangaleti, C., Schveitzer, M. C., Peduzzi, M., Zoboli, E. L. C. P., \& Soares, C. B. (2017). Experiences and shared meaning of teamwork and interprofessional collaboration among health care professionals in primary health care settings: a systematic review. JBI database of systematic reviews and implementation reports, 15(11), 2723-2788. https://doi.org/10.11124/jbisrir-2016-003016

Shah, B., Forsythe, L., \& Murray, C. (2018). Effectiveness of interprofessional care teams on reducing hospital readmissions in patients with heart failure: A systematic review. Medsurg Nursing, 27(3), 177-185.

Sims, S., Hewitt, G., \& Harris, R. (2015). Evidence of collaboration, pooling of resources, learning and role blurring in interprofessional healthcare teams: a realist synthesis. Journal of interprofessional care, 29(1), 20-25. https://doi.org/10.3109/13561820.2014.939745

Sinha, A. (2017). The Role of Team Effectiveness in Quality of Health Care. Integr J Glob Health, 1, 1.

Sterling, H. K., \& Selesnick, H. L. (1988). Teamwork Effectiveness Self-Assessment Questionnaire.

Thomson, K., Outram, S., Gilligan, C., \& Levett-Jones, T. (2015). Interprofessional experiences of recent healthcare graduates: A social psychology perspective on the barriers to effective communication, teamwork, and patient-centred care. Journal of interprofessional care, 29(6), 634-640. https://doi.org/10.3109/13561820.2015.1040873

Vijayaraghavan, B. K. T., Willaert, X., \& Cuthbertson, B. H. (2018). Should ICU clinicians follow patients after 
ICU discharge? No: Springer.

Wells, S., Tamir, O., Gray, J., Naidoo, D., Bekhit, M., \& Goldmann, D. (2018). Are quality improvement collaboratives effective? A systematic review. BMJ Qual Saf, 27(3), 226-240. https://doi.org/10.1136/bmjqs-2017-006926

\section{Copyrights}

Copyright for this article is retained by the author(s), with first publication rights granted to the journal.

This is an open-access article distributed under the terms and conditions of the Creative Commons Attribution license (http://creativecommons.org/licenses/by/4.0/). 